http://ojs.stie-labuhanbatu.ac.id/index.php/

\title{
PENGARUH EDUKASI DAN SOSIALISASI SEKOLAH PASAR MODAL BURSA EFEK INDONESIA TERHADAP MOTIVASI MEMBELI SAHAM DI GALERI INVESTASI UNIVERSITAS LABUHAN BATU
}

\author{
Yudi Prayoga
}

Dosen Tetap Fakultas Ekonomi Dan Bisnis, Universitas Labuhan Batu

\begin{abstract}
ABSTRAK
Penelitian ini bertujuan untuk menguji pengaruh edukasi dan sosialisasi sekolah pasar modal terhadap motivasi membeli saham pada galeri investasi Universitas Labuhan batu khususnya pada mahasiswa jurusan manajemen Universitas Labuhan batu. Secara umum, orang-orang akan melakukan suatu tindakan apabila ada sesuatu hal yang membuat ia tertarik sehingga secara alamiah orang tersebut akan termotivasi untuk memperolehnya. Penelitian ini dilakukan di Galeri investasi Sekolah Tinggi Ilmu Ekonomi Universitas Labhuan Batu.Penelitian ini dilakukan pada bulan Maret 2019. Pendekatan yang digunakan dalam penelitian adalah penelitian kuantitatif. Tehnik pengambilan data pada penelitian ini adalah dengan menggunakan survei. Instrumen pengumpulan data yang yang digunakan pada penelitian ini adalah dengan menggunakan kuesioner (angket). Dalam hasil analisis yang dilakukan dalam penelitian didapatkan bahwa ada pengaruh yang positif dan signifikan antara edukasi dan sosialisasi sekolah pasar modal bursa efek indonesia terhadap motivasi membeli saham pada galeri investasi Universitas Labuhanbatu. Pengetahuan atau edukasi mengenai investasi mutlak dibutuhkan bagi seorang calon investor sebelum terjun ke dunia pasar modal atau bisnis. Pengetahuan yang memadai ini akan membentuk kecakapan sesorang dalam menciptakan nilai dan keuntungan dan juga mampu mengelola sebuah resiko yang ada baik kecil maupun besar sehingga mengurangi dampak kerugian yang akan dialami
\end{abstract}

Keyword : Galeri investasi, Pasar modal, Edukasi, Sosialisasi

\section{Latar Belakang Masalah}

Kampanye Yuk Nabung Saham telah dicanangkan oleh pemerintah sejak 2015, tepatnya diluncurkan pertama kali pada 12 November 2015 oleh Wakil Presiden Jusuf Kalla. Hasil kampanye tersebut cukup menggembirakan. Menurut Direktur Pengembangan BEI Nicky Hogan, pada Desember 2015 jumlah investor di pasar modal masih sekitar 434.107 orang, sedangkan pada awal 2018 sudah meningkat menjadi sekitar 635.000 investor. Hal ini menunjukkan pertumbuhan yang menggembirakan --hingga mencapai 46 persen dalam skala nasional.

Sosialisasi dan edukasi dilakukan untuk masyarakat, baik institusi maupun perorangan, dunia pendidikan, dan sosialisasi secara nasional maupun internasional (OJK, 2015). Sosialisasi dan edukasi di kampus telah dilakukan baik secara langsung maupun tidak langsung. Sosialisasi dan edukasi di lingkungan kampus secara langsung, meliputi: seminar, workshop, pelatihan, simulasi dan kompetisi baik tingkat regional maupun nasional, bahkan sampai tingkat 
internasional. Dilain sisi, pihak kampus dan pihak Bursa PT Efek Indonesia juga melakukan kerjasama dalam pembentukan galeri investasi di setiap kampus guna mendorong investor investor baru didalam institusi pendidikan dan dari dunia luar.

Walaupun kampanye menabung saham sudah dilakukan secara masif oleh KSPM (Kelompok Studi Pasar Modal), masih banyak persepsi-persepsi negatif dari mahasiswa terkait menabung atau investasi dalam saham. Salah satu persepsi tersebut yaitu masih banyak masyarakat yang menganggap investasi saham termasuk ke dalam perjudian. Masyarakat sering menyebut dengan kata "bermain saham" yang memiliki konotasi dengan bermain-main dengan perjudian. Hal tersebut tidak bisa di salahkan sepenuhnya karena ini atas ketidak tahuan tentang pasar modal itu sendiri. Kadang mereka menganggap saham bagaikan sebuah permainan angka yang mempunyai tingkat spekulasi tinggi. Bahkan tiap detik angka-angka dalam running trade akan terus menampilkan harga saham yang berubah ketika jam perdagangan buka. Agar anggapan perjudian tersebut dapat hilang di masyarakat, kita perlu memberikan beberapa edukasi. Berinvestasi di saham artinya kita membeli persentase kepemilikan atas sebuah perusahaan. Selanjutnya kenali dulu saham yang akan kita beli, jangan asal membeli saham yang kita tidak tahu kesehatan perusahaannya. Dukungan dari para perusahaan sekuritas pun juga dilakukan, terutama dalam memberikan akses kemudahan bagi para mahasiswa untuk mulai membuka rekening dan memulai trading, yaitu hanya dengan Rp. 100.000,00 sudah dapat melakukan transaksi.

Begitu banyak kemudahan yang diberikan mulai dari akses sampai memulai trading dengan jumlah yang kecil, akan tetapi motivasi mahasiswa untuk membeli saham pada galeri investasi Universitas Labuhan Batu masih cukup rendah. Hal ini dipertegas dalam penelitian Khotimah, Warsini, \& Nuraeni (2016) yang mengaskan bahwa sosialisasi dan pengetahuan berpengaruh terhadap minat investasi di pasar modal pada efek syariah. Hasil penelitian Peristiwo (2016) menunjukkan bahwa rendahnya minat investasi disebabkan karena kurangnya edukasi dan sosialisasi terutama berkaitan dengan efek syariah.

Dengan demikian, penelitian bertujuan untuk mengidentifikasi peran sosialisasi dan edukasi terhadap Motivasi investasi di pasar modal. Secara khusus penelitian ini bertujuan untuk mengidentifikasi berbagai sosialisasi dan edukasi yang sudah dilakukan, mengidentifikasi peranan media sosialiasai terhadap minat investasi, mengidentifikasi faktor pendukung dan penghambat, serta menganalisis efektivitas sosialisasi dan edukasi pasar modal.

\section{METODE PENELITIAN}

Penelitian ini dilakukan di Galeri investasi Sekolah Tinggi Ilmu Ekonomi Universitas Labhuan Batu.Penelitian ini dilakukan pada bulan Maret 2019. Pendekatan 
yang digunakan dalam penelitian adalah penelitian kuantitatif. Tehnik pengambilan data pada penelitian ini adalah dengan menggunakan survei. Instrumen pengumpulan data yang yang digunakan pada penelitian ini adalah dengan menggunakan kuesioner (angket). Dalam penelitian ini, peneliti mengajukan beberapa kriteria sebagai populasi adalah sebagai berikut:

1. Mahasiswa STIE Universitas Labuhan Batu

2. Telah Lulus Mata Kuliah Manajemen Investasi

Berdasarkan kriteria yang telah ditentukan, maka populasi yang akan diambil dalam penelitian ini adalah mahasiswa STIE Universitas Labuhan Batu angkatan 2015 dan 2016 atau pada semester 6 dan 8.Populasi ini diambil dengan alasan selain telah memenuhi syarat kriteria sampel,juga untuk menjaga tingkat proposional sampel sehingga jumlah sampel yang diambil mewakili keseluruhan sampel. dibawah ini akan dideskripsikan dalam bentuk tabel.

Tabel. 1. Deskripsi penentuan populasi

\begin{tabular}{|l|c|c|}
\hline \multicolumn{1}{|c|}{ Deskripsi } & $\begin{array}{c}\text { Angkatan 2015 } \\
\text { (Semester 6) }\end{array}$ & $\begin{array}{c}\text { Angkatan 2016 } \\
\text { (Semester 8) }\end{array}$ \\
\hline Jumlah Mahasswa & 80 & 75 \\
\hline Jumlah Populasi & \multicolumn{2}{|c|}{$\mathrm{N}=155$} \\
\hline
\end{tabular}

Dalam penelitian ini peneliti menggunakan rumus Slovin dalam penentuan besarnya sampel yang akan digunakan yaitu dengan rumus $\mathrm{n}=\mathrm{N} /\left(1+\left(\mathrm{N} \mathrm{x} \mathrm{e}^{2}\right)\right)$ maka akan didapat hasil sebanyak 112 orang .

Penelitian ini menggunakan dua sumber data, yaitu data primer dan sekunder Data primer merupakan data yang diperoleh secara langsung dari lapangan, tanpa melalui pihak ke tiga (Bungin, 2010). Dalam hal ini berupa data yang diperoleh melalui penyebaran kuesioner. melalui penyebaran angket (kuesioner). Sementara itu, data sekunder merupakan data yang diperoleh melaui pihak ketiga yang berupa hasil riset terdahulu yang memiliki keterkaitan, dan sumber-sumber lain berupa data dari website yang berkaitan serta dapat memberikan informasi yang dibutuhkan

Metode analisis dan penyajian data menggunakan pendekatan kuantitatif deskriptif. Penyajian data dalam penelitian ini yaitu dengan mengidentifikasi dan mendeskripsikan berbagai temuan lapangan tentang sosialisasi dan edukasi pasar modal , yang meliputi:

1. Identifikasi apakah edukasi pasar modal bursa efek indonesia berpengaruh terhadap motivasi pembelian saham pada galeri investasi Universitas Labuhan Batu 
2. Identifikasi apakah sosialisasi sekolah pasar modal bursa efek indonesia berpengaruh terhadap motivasi pembelian saham pada galeri Investasi Universitas Labuhan Batu

3. Identifikasi apakah edukasi dan sosialisasi sekolah pasar modal bursa efek indonesia berpengaruh terhadap motivasi pembelian saham pada galeri Investasi Universitas Labuhan Batu

\section{HASIL DAN PEMBAHASAN}

Dalam penelitian ini peneliti menggunakan aplikasi pengolahan data statistik SPSS versi 22. Aplikasi ini diharapkan dapat membantu dalam menyelesaikan data statistik yang didapatkan dalam penelitian. Data yang diolah adalah data yang diambil langsung kepada responden dengan menggunakan kuisioner yang disebarkan.

\section{Regresi Sederhana}

Pengolahan data dalam uji analisis regresi sederhana dengan SPSS, peneliti terlebih dahulu melakukan Uji Normalitas, Uji linieritas dan Uji heteroskedastisitas sedangkan dengan uji autokorelasi peneliti tidak melakukan dikarenakan data ini bukan ermasuk data time series atau data runtun waktu, dan hasil analisis dari ke 3 uji diatas sudah lolos dalam syarat kelayakan model regresi linier sederhana.

Analisis regresi sederhana adalah hubungan secara linier antara satu variabel independen $(\mathrm{X})$ dan variabel dependen $(\mathrm{Y})$. Analisis ini digunakan untuk mengetahui arah hubungan antara variabel. Berikut merupakan ringkasan dari hasil korelasi ketiga variabel pada penelitian ini:

1. Identifikasi apakah edukasi pasar modal bursa efek indonesia berpengaruh terhadap motivasi pembelian saham pada galeri investasi Universitas Labuhan Batu

Tabel 2. Hasil output SPSS Variabel Edukasi

\section{Coefficients $^{a}$}


http://ojs.stie-labuhanbatu.ac.id/index.php/

\begin{tabular}{|c|c|c|c|c|c|c|}
\hline \multirow{2}{*}{\multicolumn{2}{|c|}{ Model }} & \multicolumn{2}{|c|}{ Unstandardized Coefficients } & \multirow{2}{*}{$\begin{array}{c}\text { Standardized } \\
\text { Coefficients }\end{array}$} & \multirow[b]{2}{*}{$\mathrm{t}$} & \multirow[b]{2}{*}{ Sig. } \\
\hline & & B & Std. Error & & & \\
\hline 1 & (Constant) & 3,384 & 1,077 & & 3,142 & ,002 \\
\hline & Edukasi & ,850 & ,057 & ,771 & 14,952 & ,000 \\
\hline
\end{tabular}

Berdasarkan hasil dari output SPSS tersebut, dapat diketahui dari tabel diatas yakni:

a. Angka konstanta dari unstandardized coeffisients nilainya sebesar 3,384. angka ini merupakan angka konstan yang mempunyai artibahwa jika tidak ada Edukasi (X1) maka nilai konsisten Motivasi Investasi (Y) adalah sebesar 3.384

b. Angka koefisien regresi nilainya sebesar 0.850. angka ini mengandung arti bahwasetiap penambahan $1 \%$ Edukasi (X1) maka Motivasi Investasi akan meningkat 0.850 .

c. Nilai Koefisien regresi bernilai (+), maka dengan demikian dapat dikatakan bahwa Edukasi Pasar modal (X1) berpengaruh positif terhadap Motivasi Investasi pasar modal. sehimgga persamaanya adalah $\mathrm{Y}=3,384+0,850 \mathrm{X}$

d. Berdasarkan Output diatas diketahui nilai signifikansi (sig) sebesar 0,000 lebih kecil dari < Probabilitas 0,05 sehingga dapat disimpulkan bahwa ada pengaruh Edukasi pasar modal terhadap motivasi investasi saham digaleri investasi Universitas Labuhanbatu

2. Identifikasi apakah sosialisasi sekolah pasar modal bursa efek indonesia berpengaruh terhadap motivasi pembelian saham pada galeri Investasi Universitas Labuhan Batu

Tabel 3. Hasil Output SPSS variabel Sosialisasi 
Coefficients $^{\mathrm{a}}$

\begin{tabular}{|c|c|c|c|c|c|}
\hline \multirow[b]{2}{*}{ Model } & \multicolumn{2}{|c|}{ Unstandardized Coefficients } & \multirow{2}{*}{$\begin{array}{c}\begin{array}{c}\text { Standardized } \\
\text { Coefficients }\end{array} \\
\text { Beta }\end{array}$} & \multirow[b]{2}{*}{$t$} & \multirow[b]{2}{*}{ Sig. } \\
\hline & B & Std. Error & & & \\
\hline (Constant) & 7,401 & 1,188 & & 6,229 & ,000 \\
\hline Sosialisasi & 778 & 077 & ,635 & 10,168 & ,000 \\
\hline
\end{tabular}

Berdasarkan hasil dari output SPSS tersebut, dapat diketahui dari tabel diatas yakni:

a. Angka konstanta dari unstandardized coeffisients nilainya sebesar 7,401. angka ini merupakan angka konstan yang mempunyai artibahwa jika tidak ada Sosialisasi (X2) maka nilai konsisten Motivasi Investasi (Y) adalah sebesar 7,401

b. Angka koefisien regresi nilainya sebesar 0,778. angka ini mengandung arti bahwasetiap penambahan $1 \%$ Sosialisasi (X2) maka Motivasi Investasi akan meningkat 0,778 .

c. Nilai Koefisien regresi bernilai (+), maka dengan demikian dapat dikatakan bahwa Edukasi Pasar modal (X1) berpengaruh positif terhadap Motivasi Investasi pasar modal. sehimgga persamaanya adalah $\mathrm{Y}=7,401+0,778 \mathrm{X} 2$

d. Berdasarkan Output diatas diketahui nilai signifikansi (sig) sebesar 0,000 lebih kecil dari < Probabilitas 0,05 sehingga dapat disimpulkan bahwa ada pengaruh Sosialisasi pasar modal terhadap motivasi investasi saham digaleri investasi Universitas Labuhanbatu

3. Identifikasi apakah edukasi dan sosialisasi sekolah pasar modal bursa efek indonesia berpengaruh terhadap motivasi pembelian saham pada galeri Investasi Universitas Labuhan Batu

Tabel 4. Hasil Output SPSS Uji F 
ANOVA $^{\mathrm{a}}$

\begin{tabular}{|r|r|r|r|r|r|}
\hline \multicolumn{1}{|l|}{ Model } & Sum of Squares & df & Mean Square & F & Sig. \\
\hline $1 \quad$ Regression & 428,715 & 2 & 214,358 & 115,263 &, $000^{\mathrm{b}}$ \\
& 282,679 & 152 & 1,860 & & \\
Residual & 711,394 & 154 & & & \\
\hline & & & & & \\
\hline
\end{tabular}

Dari hasil uji F pada tabel 4 diperoleh nilai Fhitung $<5 \%(0,000<0,05)$ atau dapat disimpulkan bahwa Edukasi dan Sosialisai sekolah pasar modal secara simultan berpengaruh terhadap motivasi membeli saham pada galeri investasi Universitas Labuhan batu.

\section{KESIMPULAN}

Penelitian ini bertujuan untuk menguji pengaruh edukasi dan sosialisasi sekolah pasar modal terhadap motivasi membeli saham pada galeri investasi Universitas Labuhan batukhususnya pada mahasiswa jurusan manajemen Universitas Labuhan batu. Secara umum, orang-orang akan melakukan suatu tindakan apabila ada sesuatu hal yang membuat ia tertarik sehingga secara alamiah orang tersebut akan termotivasi untuk memperolehnya.

Dalam dunia bisnis, ada banyak hal yang mampu mendorong seseorang untuk bisa termotivasi agar mau bergabung dalam kegiatan bisnis tersebut. Salah satu diantaranya adalah adanya return atau keuntungan yang ditawarkan. Selain return atau keutungan, hal lain yang perlu dipertimbangkan adalah faktor penghambatnya yakni kemungkinan adanya masalah dan resiko yang akan dihadapi kedepannya. Faktor resiko inilah yang menjadi bahan pertimbangan calon investor untuk dapat melakuakn investasi atau tidak berinvestasi di pasar modal. Oleh karena itu, pada penelitian ini para mahasiswa diberikan angket berupa pertanyaan mengenai return dan juga resiko berinvestasi sebagai bahan pertimbanganya.

Pengetahuan atau edukasi mengenai investasi mutlak dibutuhkan bagi seorang calon investor sebelum terjun ke dunia pasar modal atau bisnis. Pengetahuan yang memadai ini akan membentuk kecakapan sesorang dalam menciptakan nilai dan keuntungan dan juga mampu mengelola sebuah resiko yang ada baik kecil maupun besar sehingga mengurangi dampak kerugian yang akan dialami. Bagi mahasiswa khususnya mahasiswa manajemen yang telah menempuh mata kuliah portofolio dan manajemen keuangan, tentunya hal tersebut sudah menjadi salah satu pondasi dasar dan juga modal untuk dapat bisa bergabung dunia investasi pasar modal sehingga memilki kemampuan analisis dalam meakukan investasi pada pasar modal.

\section{DAFTAR PUSTAKA}


http://ojs.stie-labuhanbatu.ac.id/index.php/

Annonim. (2015). 5 hal yang harus Anda ketahui sebelum berinvestasi. Di unduh pada tanggal 30 November 2019 dari http://www.logikabisnis.com /5-hal-yang-harus-anda-ketahui-sebelumberinvestasi/.

Annonim. (2015). 7 hal yang harus Anda pertimbangkan sebelum berin vestasi disaham. Di unduh pada tanggal 30 November 2019 dari http: /www.logikabisnis.com/7-hal-yang-harus-andapertimbangkan-sebelum-berinvestasi-di-saham/.

Audriene, D. (2016). BEI Bidik Mahasiswa Sebagai Investor Saham Baru. Diunduh pada tanggal 28 November 2019 dari http://www.cnn indonesia.com/ekonomi/20160517180417-78131405/bei-bidik-mahasiswa-sebagai-investor-saham-baru/.

Fahriani, D. (2012). Pengaruh Motivasi Terhadap Minat Mahasiswa Akuntansi Untuk Mengikuti Pendidikan Profesi Akuntansi (PPAK).Jurnal Ilmu \& Riset Akuntansi Vol. 1 No. 12 (2012).

Hadi, N. (2013). Acuan Teoritis dan Praktis Investasi di Instrumen Keuangan Pasar Modal. Yogyakarta: Graha Ilmu.

Hendy MF \& Tjiptono D. (2001). Pasar Modal di Indonesia, Pendekatan Tanya Jawab. Jakarta: Salemba Empat.

Hutagalung, M.N. (2015). Definisi Return Saham Menurut Ahli . Diunduh pada tanggal 2 Desember 2019 dari http://kumpulan-artikel-sekolah. blogspot.co.id/ 2015/10/definisi-returnsaham-menurut-ahli.html.

Khotimah, H., Warsini. S., \& Nuraeni, Y. (2016). Pengaruh Sosialisasi dan Pengetahuan Terhadap Minat Investor Pada Efek Syariah di Pasar Modal (Survei Pada Nasabah PT Danareksa Sekuritas Cabang FE-UI Depok). Jurnal terbitan Politeknik Negeri Jakarta, Halaman 423.

Kismono, G. (2011). Bisnis Pengantar $\left(2^{r d} e d\right)$. Yogyakarta: BPFE.

Komar. (2016). BEI Catat Kenaikan Jumlah Investor Saham. Diunduh pada tanggal 28 November 2016 dari http://www.topsaham.com/index.php/opi ni/item/955-bei-catat-kenaikan-jumlahinvestor-saham. 